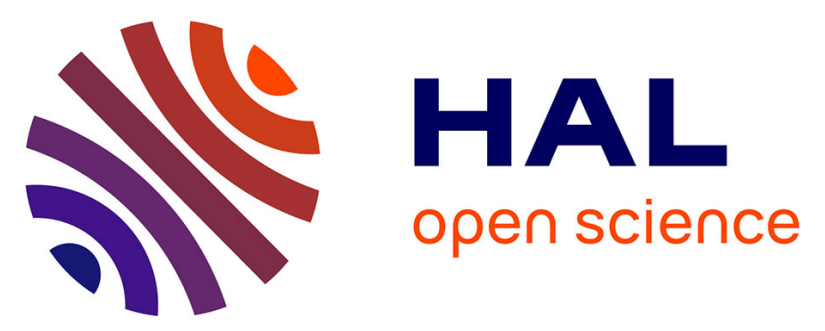

\title{
Integration of fiber Bragg grating temperature sensors in plasma facing components of the WEST tokamak
} Yann Corre, Guillaume Laffont, Christine Pocheau, Romain Cotillard, Jonathan Gaspar, Nicolas Roussel, Mehdi Firdaouss, J.L. Gardarein, Dominique Guilhem, Marc Missirlian

\section{To cite this version:}

Yann Corre, Guillaume Laffont, Christine Pocheau, Romain Cotillard, Jonathan Gaspar, et al.. Integration of fiber Bragg grating temperature sensors in plasma facing components of the WEST tokamak. Review of Scientific Instruments, 2018, 89 (6), pp.063508. 10.1063/1.5024514 . hal-02011117

\section{HAL Id: hal-02011117 https://hal.science/hal-02011117}

Submitted on 7 Feb 2019

HAL is a multi-disciplinary open access archive for the deposit and dissemination of scientific research documents, whether they are published or not. The documents may come from teaching and research institutions in France or abroad, or from public or private research centers.
L'archive ouverte pluridisciplinaire HAL, est destinée au dépôt et à la diffusion de documents scientifiques de niveau recherche, publiés ou non, émanant des établissements d'enseignement et de recherche français ou étrangers, des laboratoires publics ou privés. 


\section{AUTHOR QUERY FORM}

\begin{tabular}{|l|l|l|}
\hline & Journal: Rev. Sci. Instrum. & $\begin{array}{l}\text { Please provide your responses and any corrections by annotating this } \\
\text { PDF and uploading it according to the instructions provided in the proof } \\
\text { notification email. }\end{array}$ \\
\hline Publishing & Article Number: 069806RSI & \\
\hline
\end{tabular}

\section{Dear Author,}

Below are the queries associated with your article. Please answer all of these queries before sending the proof back to AIP.

Article checklist: In order to ensure greater accuracy, please check the following and make all necessary corrections before returning your proof.

1. Is the title of your article accurate and spelled correctly?

2. Please check affiliations including spelling, completeness, and correct linking to authors.

3. Did you remember to include acknowledgment of funding, if required, and is it accurate?

\begin{tabular}{|c|c|}
\hline $\begin{array}{l}\text { Location in } \\
\text { article }\end{array}$ & $\begin{array}{l}\text { Query/Remark: click on the } Q \text { link to navigate } \\
\text { to the appropriate spot in the proof. There, insert your comments as a PDF annotation. }\end{array}$ \\
\hline Q1 & $\begin{array}{l}\text { Please check that the author names are in the proper order and spelled correctly. Also, please ensure that each author's given and } \\
\text { surnames have been correctly identified (given names are highlighted in red and surnames appear in blue). }\end{array}$ \\
\hline Q2 & We have reworded the sentence beginning "The sensors used in..." for clarity. Please check that your meaning is preserved. \\
\hline Q3 & We have reworded the sentence beginning "Although the accuracy of..." for clarity. Please check that your meaning is preserved. \\
\hline Q4 & In the sentence beginning "In remote areas...," please suggest if "path" can be changed as "pass." \\
\hline Q5 & Please reword the sentence beginning with "As the completion..." so that your meaning will be clear to the reader. \\
\hline Q6 & Please define SGL at first occurrence. \\
\hline Q7 & In the sentence beginning "the main issues are...," please check the usage of "in one side" and "in the other side" for clarity. \\
\hline Q8 & We have reworded the sentence beginning "Standard multiplexed FBGs..." for clarity. Please check that your meaning is preserved. \\
\hline Q9 & In the sentence beginning "The thermal condition...," please confirm that "the previous section" refers to Sec. III. \\
\hline Q10 & In the sentence beginning "The temperature is first...," please check the usage of "heating is switch-off" for clarity. \\
\hline Q11 & Please check the definition of CAD. \\
\hline Q12 & In the sentence beginning, "The overall is...," please check the usage of the word "overall." \\
\hline Q13 & $\begin{array}{l}\text { In the sentence beginning "Among the tested...," please check and suggest if the phrase "temperature furnace" can be changed to } \\
\text { "furnace temperature." }\end{array}$ \\
\hline Q14 & In the sentence beginning with "After the test and...," please check the usage of "standalone" for clarity. \\
\hline Q15 & Please reword the sentence beginning with "The full FBG system..." so that your meaning will be clear to the reader. \\
\hline Q16 & In the sentence beginning "The reflected power...," please check the usage of "the two first" for clarity. \\
\hline Q17 & Please define TTBB at first occurrence. \\
\hline Q18 & In the sentence beginning "Figures 15(a) and...," please check the usage of "temperature rise" for clarity. \\
\hline Q19 & Please define TCI at first occurrence. \\
\hline Q20 & In the sentence beginning "Such a temperature rise...," please check the usage of "temperature rise" for clarity. \\
\hline Q21 & We have reworded the sentence beginning "Four high temperature..." for clarity. Please check that your meaning is preserved. \\
\hline Q22 & We have reworded the sentence beginning "This work has been..." for clarity. Please check that your meaning is preserved. \\
\hline
\end{tabular}


Continued from previous page.

Q23

We were unable to locate a digital object identifier (doi) for Refs. 8, 10, 13, and 14. Please verify and correct author names and journal details (journal title, volume number, page number, and year) as needed and provide the doi. If a doi is not available, no other information is needed from you. For additional information on doi's, please select this link: http//www.doi.org/.

Q24

Please confirm the page number in Ref. 17, as we have inserted the required information.

Q25

Footnote to the text is not allowed as per journal style. Therefore, we have added it to the reference list as Ref. 19 and updated the citations in text. Please check and confirm.

Thank you for your assistance. 


\title{
Integration of fiber Bragg grating temperature sensors in plasma facing components of the WEST tokamak
}

\author{
Y. Corre, ${ }^{1, a)}$ G. Laffont, ${ }^{2}$ C. Pocheau, ${ }^{1}$ R. Cotillard, ${ }^{2}$ J. Gaspar, ${ }^{1}$ N. Roussel, ${ }^{2}$ \\ M. Firdaouss, ${ }^{1}$ J.-L. Gardarein, ${ }^{3}$ D. Guilhem, ${ }^{1}$ and M. Missirlian ${ }^{1}$ \\ ${ }^{1}$ CEA, IRFM, F-13108 Saint-Paul-lez-Durance, France \\ ${ }^{2}$ CEA, LIST, Gif-sur-Yvette Cedex 91191, France \\ ${ }^{3}$ Aix-Marseille Université, CNRS, IUSTI UMR 7343, 13013 Marseille, France
}

(Received 1 February 2018; accepted 4 June 2018; published online XX XX XXXX)

\begin{abstract}
Plasma Facing Components (PFC) temperature measurement is mandatory to ensure safe high power and long pulse tokamak operation. IR thermography systems which are widely used in magnetic fusions devices become challenged with the choice of tungsten as a PFC material in the ITER tokamak, mainly due to emissivity uncertainties and reflection issues in a hot environment. Embedded temperature measurements are foreseen to cross-check the IR thermography measurements. Fiber Bragg grating sensors are potentially of great interest for this application because they are immune to electromagnetic interference and allow the measurement of a large number of temperature spots on a single fiber. Four optical fiber temperature sensing probes, each of them including 11 regenerated fiber Bragg gratings equally spaced by $12.5 \mathrm{~mm}$ (equivalent to one ITER-like tungsten monoblock), have been specifically designed and manufactured for the WEST project (W-tungsten Environment and Steady State Tokamak). The four probes are embedded in W-coated graphite components at two different distances from the surface, $3.5 \mathrm{~mm}$ and $7 \mathrm{~mm}$, to cover a wide range of temperatures up to 900 ${ }^{\circ} \mathrm{C}$. This paper addresses the design and integration issues and the qualification and performance assessment performed in the laboratory. It also shows the first measurements of this new diagnostic achieved in a tokamak environment during baking of the machine and during early diverted plasma exposure. Published by AIP Publishing. https://doi.org/10.1063/1.5024514
\end{abstract}

\section{INTRODUCTION}

Fiber Bragg Gratings (FBGs) are well-established strain and temperature transducers finding numerous applications in both scientific and industrial fields. ${ }^{1}$ They present great interest in the field of nuclear fusion research because they are immune to electromagnetic interference (EMI). FBG strain or temperature sensors are foreseen in the ITER tokamak in the magnet structure (temperature between $4.5 \mathrm{~K}$ and $300 \mathrm{~K}$ ), ${ }^{2}$ in the helium cooled lithium lead Test Blanket Module ${ }^{3}$ and also in the vacuum vessel. ${ }^{4}$ Such applications rely on specifically developed optical fiber-based sensors that should be tested in a real tokamak environment before integration in the ITER environment. FBG strain gauges and temperature sensors have successfully been developed and installed in the Joint European Torus (JET) ${ }^{5}$ and ASDEX Upgrade (AUG) ${ }^{6}$ tokamaks to measure forces induced on the vacuum vessel during disruption and deformation of the passive stabilizing loop induced during plasma experiment, respectively. In both cases, FBG sensors were fixed to components located in remote areas, not directly exposed to the plasma heat load: on the top and bottom vessel restraints support (legs) in JET and on the copper surface of the stabilizing loops in AUG. The sensors used in JET and AUG are therefore working mainly in the low temperature or medium range, typically below $400{ }^{\circ} \mathrm{C}$; thereafter, the Bragg grating may vanish. ${ }^{7} \mathrm{FBG}$ temperature measurement beyond $400{ }^{\circ} \mathrm{C}$ is a challenging task

a) Author to whom correspondence should be addressed: yann.corre@cea.fr and currently a major research topic. Among the various solutions considered to develop temperature-resistant FBGs, the regeneration process ${ }^{1}$ shows that the $\mathrm{FBG}$ can survive above $900{ }^{\circ} \mathrm{C}$ with long-term use $(>9000 \mathrm{~h})$. This is potentially of great interest to monitor the bulk temperature of the Plasma Facing Components (PFCs) and what we propose to test in the WEST (W-tungsten Environment and Steady State Tokamak) project. $^{8}$

The WEST project consists in transforming the Tore Supra tokamak in an X-point divertor configuration while keeping its long pulse capability, in order to test the ITER divertor technology. ${ }^{8}$ The main goal is to test the actively cooled tungsten (W) Plasma Facing Units (PFUs) representative of the ITER divertor target ${ }^{9,10}$ under high heat load (in the $10-20 \mathrm{MW} \mathrm{m}^{-2}$ range). In WEST, each PFU is composed of $35 \mathrm{~W}$ monoblocks of individual size $28 \mathrm{~mm} \times 12 \mathrm{~mm} \times 26 \mathrm{~mm}$ (width $\times$ depth $\times$ height) assembled with a gap of $0.5 \mathrm{~mm}$ on a $\mathrm{CuCrZr}$ heat sink tube. ${ }^{11}$ As the completion of the ITER-like target in WEST is expected to require more time than the tokamak platform, it is planned to start the operation in 2017 with a mix of actively cooled ITER-like PFUs made of tungsten and non-actively cooled PFUs made of graphite with a thin coating of tungsten $(\sim 15 \mu \mathrm{m})$ in the lower divertor. ${ }^{12}$ Under high heat load, the $\mathrm{W}$-coated graphite component will rapidly heat, which affords an opportunity to test the regenerated FBG technology in a real tokamak environment with high temperature excursion (up to or beyond $1000{ }^{\circ} \mathrm{C}$ ). Graphite is easy to machine, it is a low cost component, and it has no risk of crack formation such as tungsten after machining the space to 
house the diagnostic (hole or groove). In order to test the feasibility to monitor the PFU bulk temperature, we have designed and manufactured 4 temperature sensors including 11 gratings. Probes are embedded in a side groove of the graphite component at two different distances from the surface. One groove is machined at $7 \mathrm{~mm}$ from the surface to test the FBG below $800^{\circ} \mathrm{C}$ (lower FBG) and ensure the proper functioning of the FBG diagnostic and one groove at $3.5 \mathrm{~mm}$ to test the FBG beyond $800{ }^{\circ} \mathrm{C}$ (upper FBG) in order to find the maximum temperature threshold with the FBG system developed for WEST.

This paper is organized as follows. The diagnostic specification, WEST environment, and thermal behavior of the W-coated graphite PFU are summarized in Sec. II. The FBG design and setup optimized according to the thermal behavior of the components, as well as the signal processing, are presented in Sec. III. The integration of the fiber in the W-coated graphite PFU and the cabling through the tokamak environment are presented in Sec. IV. The FBG system, standalone or mounted in the PFU, is tested and characterized in laboratory experiments with the thermostatically controlled water bath, tubular furnace, and halogen lamps (Sec. V). First experimental results obtained during baking and early diverted plasma exposure with the FBG diagnostic installed in the WEST tokamak are presented in Sec. VI.

\section{SPECIFICATION AND ENVIRONMENT OF THE WEST FBG DIAGNOSTIC}

\section{A. Diagnostic specification and requirements}

The goal of the FBG diagnostic (called DTFIB\#1) in WEST is to monitor the bulk temperature in order to (1) protect the component and its coating to avoid any excessive thermal dilatation and cracks formation, ${ }^{12}$ (2) cross-calibrate the IR thermography system which is disturbed by the emissivity uncertainties and potential reflection in the hot environment, ${ }^{13}$ (3) compute the plasma heat load as depicted in Ref. 14, and finally (4) test the feasibility to use an FBG system directly into the PFCs. In this context, the diagnostic specifications and requirements are defined as follows:

- The number of fibers to be installed in the tokamak is 4 in order to focus on the feasibility first and investigate the stability of the measurement at different toroidal locations, assuming that the heat load is the same (toroidal symmetry) before any further deployment in the machine which is foreseen after the completion of the full actively cooled divertor (DTFIB\#2 project currently under progress).

- Temperature measurement is in the range of $70^{\circ} \mathrm{C}$ without any plasma (minimum temperature of the machine foreseen in ITER) and $1200{ }^{\circ} \mathrm{C}$ during plasma discharge. The accuracy of the system should be about $20^{\circ} \mathrm{C}$ at high temperature.

- The size of the grating and positioning of the Bragg peaks in the spectral bandwidth have to be defined in order to measure the temperature gradient at the FBG sensor up to $45^{\circ} \mathrm{C} / \mathrm{mm}$ (because the plasma heat load is peaked on the surface ${ }^{14}$ ).
- The number of FBGs is 11 by fiber to cover the spatial extent of the plasma heat load along the W-coated graphite PFU. Each of them is equally spaced by 12.5 $\mathrm{mm}$ which is the typical width of $\mathrm{W}$ monoblocks in ITER. ${ }^{11}$

- The optical fiber should be free (to avoid any mechanical strain) and is inserted in a metallic capillary for protection during manipulation and also for the setting in the component (using graphite adhesive). The diameter of the capillary should be of the order of the $\mathrm{mm}$ to minimize the intrusive effect of the FBG on the thermal behavior of the component. The total fiber length from the sensors up to the sealing flange should be $\sim 3 \mathrm{~m}$ to reach the port flange (which is then connected to another optical fiber to join the electronic gallery where the FBG interrogator and acquisition system are based).

- The time duration of acquisition is expected to be couple of minutes with the non-actively cooled components (plasma experiment will be limited in time to avoid excessive temperature of the component ${ }^{12}$ ). Data acquisition should be $10 \mathrm{~Hz}$ at minimum (set by the thermal time response of the graphite component and a relatively short time duration of the experiment expected before the completion of the fully actively cooled divertor).

- The expected number of cycles during WEST phase I (with inertial W-coated graphite PFUs) is 2000. The diagnostic must survive for about 2 years in the tokamak.

- Acceptable degradation of the measurement (long-term drift) along the expected operation period is about $10^{\circ}$.

Most of these requirements were achieved or are expected to be feasible based on initial testing. Although the accuracy of the measurement at high temperature and long-term drift cannot be evaluated yet, this would require high power and repetitive plasma experiments which are foreseen later on during the WEST experimental program.

\section{B. WEST environment}

WEST is based on the "tokamak" concept of plasma magnetic confinement, in which the plasma is contained in a doughnut-shaped vessel (Fig. 1). The plasma is kept away from

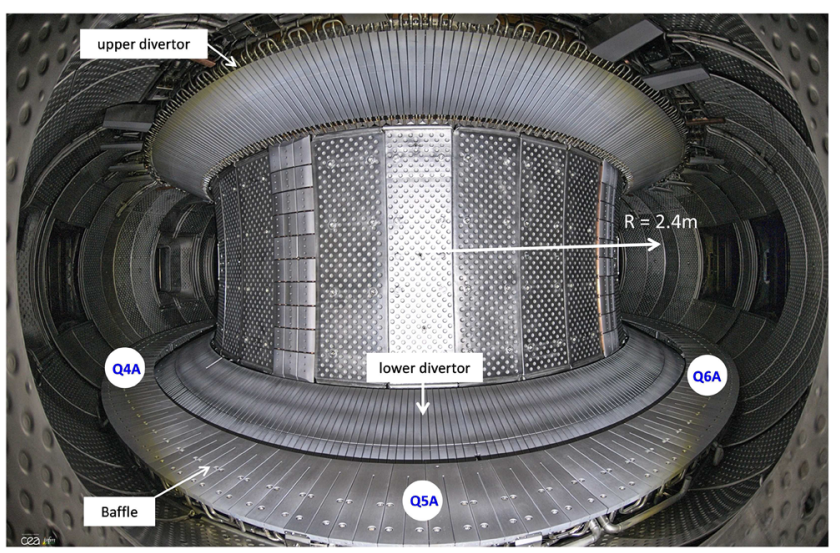

FIG. 1. Interior picture of the WEST tokamak showing the upper and lower divertor, the baffle, and port plug numbers (Q4A, Q5A, and Q6A). 
the walls by strong magnetic fields produced by superconducting coils surrounding the vessel and an electrical current driven in the plasma. WEST is characterized by a strong magnetic field (3.8 T maximum) in the plasma chamber, a vacuum condition (of the order of $10^{-5} \mathrm{~Pa}$ ), an ambient temperature of $70{ }^{\circ} \mathrm{C}$ during plasma operation and $200{ }^{\circ} \mathrm{C}$ during baking, thermo-mechanical displacement (up to few $\mathrm{mm}$ ) and vibration due to plasma instabilities, and radiation exposure such as photons, neutral particles, and neutrons. The fuel-a mixture of deuterium and hydrogen, or helium-is heated to temperatures in excess of $50 \times 10^{6}$ degrees in the core plasma. Contrary to ITER, WEST is a non-active tokamak device (there is no tritium injection), and therefore, it is not exposed to high nuclear radiation background. In WEST, the heat flux attributed to the plasma is of the order of $10 \mathrm{MW} \mathrm{\textrm {m } ^ { - 2 }}$ on targets. In remote areas, between the divertor and baffle where the cabling has to path through, the heat flux attributed to radiation and neutral particles is of the order of $10 \mathrm{~kW} \mathrm{~m}{ }^{-2} .{ }^{15}$ The device should achieve steady-state and high power plasma operation up to $1000 \mathrm{~s}$ after the completion of the full actively cooled divertor target. The diagnostic sensor should be installed in the lower divertor, while the acquisition system (FBG interrogator) is located outside the vacuum chamber (after passing through the vacuum-tight access), in the electronic gallery about $50 \mathrm{~m}$ away from the machine.

\section{WEST lower divertor and thermal behavior of the W-coated graphite PFUs}

The lower divertor is made of 12 sectors of 38 PFUs each (each sector having $30^{\circ}$ toroidal extension). As the completion of the ITER-like target is expected to require more time than the tokamak platform, it is planned to start the operation in 2017 with 6 actively cooled ITER-like PFUs (in which three are manufactured by Japanese industrial and three by Chinese industrial) and 450 non-actively cooled PFUs made of graphite with a thin coating of tungsten $(\sim 15 \mu \mathrm{m})$ in the lower divertor (see Fig. 1). Each individual graphite PFU is divided into two parts, the High Field Side (HFS) and Low Field Side (LFS) PFU. The size of the W-coated graphite PFUs is about $30 \mathrm{~mm}$ large, $26 \mathrm{~mm}$ thick (height), and $326 \mathrm{~mm}$ and $256 \mathrm{~mm}$ long for the HFS and LFS PFU, respectively. The FBG diagnostic is installed in the LFS PFU because the heat load is expected to be higher on this part. The material used is graphite R6710 from SGL (with the thermal conductivity of $\mathrm{K} \sim 82 \mathrm{~W} \mathrm{~m}^{-1} \mathrm{~K}^{-1}$ at $\mathrm{T}=200{ }^{\circ} \mathrm{C}$ ), and the $\mathrm{W}$-coating is about $15 \mu \mathrm{m}$ thick. Surface temperature should be limited to $1200{ }^{\circ} \mathrm{C}$ for standard operation and further (up to $1800{ }^{\circ} \mathrm{C}$ ) for a limited number of experiments to avoid delamination of the $\mathrm{W}$-coating. ${ }^{12}$

The thermal behavior of the W-coated graphite PFU is simulated with finite-element calculation performed with the ANSYS code, as depicted in Ref. 14. The plasma heat load distribution, $\mathrm{q}_{\mathrm{n}}\left(\mathrm{MW} \mathrm{m} \mathrm{m}^{-2}\right)$, in the poloidal direction is computed with the heuristic formulation (Gaussian-like distribution), built with IR thermography measurement during carbon-wall operation, ${ }^{16}$

$$
q_{n}(x) \propto \exp \left[\left(\frac{S}{2 \lambda_{q}}\right)^{2}-\frac{x-x_{0}}{\lambda_{q} f_{x}}\right] \operatorname{erfc}\left(\frac{S}{2 \lambda_{q}}-\frac{x-x_{0}}{S f_{x}}\right),
$$

where $x$ is the position along the target, $x_{0}$ is the strike point position (i.e., the connection of the separatrix with the target), $\lambda_{\mathrm{q}}$ is the heat flux decay length parameter in the edge plasma region ${ }^{19}$ at the outboard midplane (usually called the scrapeoff layer width of the order of few mm size), $S$ is the power spreading factor in the "private" region (i.e., the magnetically shadowed region), and $f_{x}$ is the magnetic flux expansion from the outboard midplane to the PFU. The temperature distributions reported at three different depths (surface, FBG upper, and FBG lower locations) in the graphite PFU located on the LFS are presented in Fig. 2 for the nominal high heat flux scenario (i.e., with peak heat load $\mathrm{q}_{\mathrm{n}}=10 \mathrm{MW} \mathrm{m}^{-2}$ ) and standard magnetic field configuration. After $5 \mathrm{~s}$ of heating, the surface temperature reaches almost $1400{ }^{\circ} \mathrm{C}$, while the bulk temperature is expected to be about $850{ }^{\circ} \mathrm{C}$ and $600{ }^{\circ} \mathrm{C}$ at $3.5 \mathrm{~mm}$ (FBG upper) and $7 \mathrm{~mm}$ (FBG lower) depths,
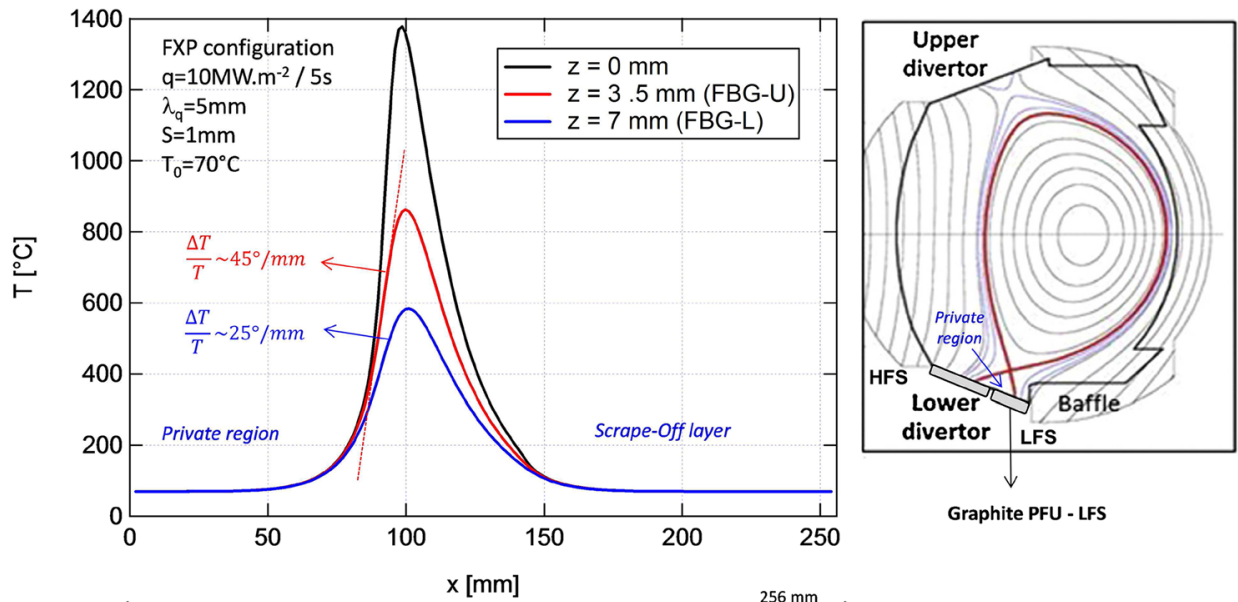

FIG. 2. (a) Temperature profile at three different locations from the surface $(z$ $=0, \mathrm{z}=3.5 \mathrm{~mm}$, and $\mathrm{z}=7 \mathrm{~mm}$ ) on the $\mathrm{W}$-coated graphite PFU located on the Low Field Side (LFS). After $5 \mathrm{~s}$ heating, the surface temperature goes up to almost $1400{ }^{\circ} \mathrm{C}$, while temperatures reported at few mms away from the surface are lower (below $1000{ }^{\circ} \mathrm{C}$ ). (b) The poloidal section of WEST showing the magnetic flux surfaces, the inner wall, and the graphite PFU housing the FBG sensor. 


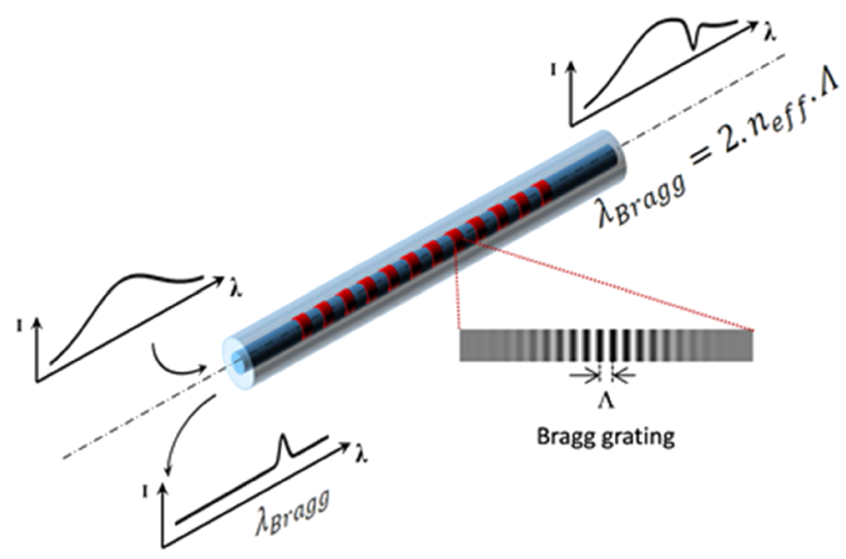

FIG. 3. Schematic picture of FBG showing the transmitted and reflected spectrum.

respectively. The predicted plasma heat flux distribution leads to a very steep temperature gradient in the component, about $45^{\circ} \mathrm{C} / \mathrm{mm}$ and $25^{\circ} \mathrm{C} / \mathrm{mm}$ in the private flux region for the upper and lower FBGs, respectively (at $3.5 \mathrm{~mm}$ and $7 \mathrm{~mm}$ below the surface). Such temperature gradients represent a challenge for the design of the multiplexed FBG; the main issues are the choice of the Bragg wavelengths in one side and the position and length of the FBG in the other side.

\section{FBG DESIGN AND SETUP FOR WEST}

\section{A. Multiplexed FBG design for WEST}

A FBG consists of a spatially periodic modulation of the refractive index created along a desired length of the core of an optical fiber. A narrow spectral band of the incident light within the fiber is reflected by successive coherent scattering from the index variations. ${ }^{17}$ The strongest interaction or mode coupling occurs at the Bragg wavelength given by

$$
\lambda_{B}=2 n_{e} \Lambda
$$

where $n_{e}$ is the effective index of refraction $(\sim 1.46)$ and $\Lambda$ is the grating period. This leads to a single peak and valley in reflected and transmitted light through the optical fiber (as shown in Fig. 3). The principle of the strain or temperature measurement is based on the determination of the wavelength shift of the Bragg peak reflected by the grating that is induced by the changes of the grating period and by the thermo-optic and elasto-optic coefficients. This "peak tracking" function is ensured by using the FBG interrogator device using a wavelength tunable laser and logarithmic trans-impedance circuits for the photo-detection. The most commonly used method to write the FBG on the fiber core is based on conventional interferometric setup with ultraviolet light taking advantage of the photosensitivity of the germano-silicate optical fiber. Multiplexed FBG aims to daisy chain multiple sensors with different Bragg wavelengths (chosen in the spectral bandwidth of the tunable laser) in order to get simultaneous measurements at different locations along a single optical fiber. Standard multiplexed FBGs for temperature measurements are commercially available below $500{ }^{\circ} \mathrm{C}$; thereafter, Bragg grating may vanish due to the erasure of the photowritten refractive index modulation. One way to extend the temperature measurement range is the regeneration process which allows increasing the temperature measurement beyond $900{ }^{\circ} \mathrm{C}$, while keeping good metrological performances. ${ }^{1}$ The thermal condition foreseen in WEST and depicted in Sec. III (Fig. 2) requires the development of specific multiplexed and regenerated FBG temperature sensors. This has been carried out in the CEA List Institute which is committed to technological innovation in digital systems including architecture, hardware, and software applied to embedded systems.

The FBG diagnostic developed in WEST is equipped with an industrial multichannel FBG interrogator, based on a wavelength tunable laser, featuring full spectrum analysis with data rate at $10 \mathrm{~Hz}$. The spectral bandwidth available to encode the FBG array is $120 \mathrm{~nm}$ covering the wavelength range from 1500 up to $1620 \mathrm{~nm}$ with a spectral resolution of $8 \mathrm{pm}$. In such a wavelength range, the thermal response of the Bragg shift varies from $10 \mathrm{pm} /{ }^{\circ} \mathrm{C}$ at $50{ }^{\circ} \mathrm{C}$ up to $20 \mathrm{pm} /{ }^{\circ} \mathrm{C}$ at $800{ }^{\circ} \mathrm{C}$ (as derived from the calibration curves), and the average value is of $14 \mathrm{pm} /{ }^{\circ} \mathrm{C}$. To cover the $70-1200{ }^{\circ} \mathrm{C}$ temperature range expected in the bulk of the $\mathrm{W}$-coated graphite PFU, the maximum shift of the Bragg peak is $15.8 \mathrm{~nm}$. Due to the limited spectral bandwidth available, it was not possible to include 11 FBG arrays with such a gap between each FBG. The maximum temperature gradient expected between two consecutive FBGs is about $500{ }^{\circ} \mathrm{C}$, which corresponds to about $7 \mathrm{~nm}$ shift of the Bragg peak. The Bragg wavelengths of two consecutive FBGs are therefore spatially spaced by $7 \mathrm{~nm}$ to avoid spectral overlapping. The Bragg wavelengths at room temperature are given in Table I.

The typical size of the gratings is about $3 \mathrm{~mm}$, and the space between two consecutive FBGs is $12.5 \mathrm{~mm}$. The eleven $12.5 \mathrm{~mm}$ spaced FBGs are simultaneously regenerated using a high-temperature annealing process, as depicted in Ref. 1. The process is performed with a homemade tubular furnace and uses a thermocouple near the FBG in order to control the temperature during the thermal treatment. During the regeneration protocol, the temperature of the furnace is raised to $920{ }^{\circ} \mathrm{C}$ which is the point triggering the regeneration for all the multiplexed FBGs. The full process, FBG photowriting, followed by the regeneration process, has been applied successfully to the four dedicated temperature probes. The FBGs are photowritten onto a $150 \mu \mathrm{m}$ diameter single-mode polyimide-coated silica-glass optical fiber inserted within a $1 \mathrm{~mm}$ diameter metallic capillary hermetically sealed at its extremity. The reflected spectrum measured at $70{ }^{\circ} \mathrm{C}$

TABLE I. Bragg wavelengths of the FBGs at room temperature.

\begin{tabular}{|c|c|c|c|c|c|c|c|c|c|c|c|}
\hline FBG & $\# 1$ & $\# 2$ & \#3 & $\# 4$ & $\# 5$ & \#6 & $\# 7$ & $\# 8$ & $\# 9$ & \#10 & \#11 \\
\hline$\lambda_{\text {Bragg }}(\mathrm{nm})$ & 1512 & 1519 & 1526 & 1533 & 1540 & 1547 & 1554 & 1561 & 1568 & 1575 & 1582 \\
\hline
\end{tabular}




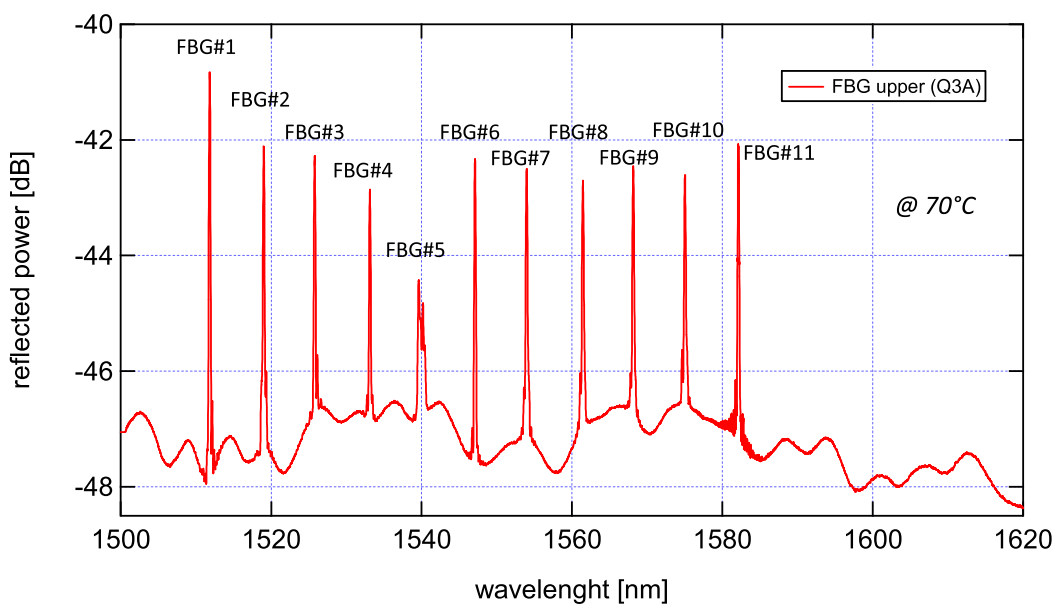

FIG. 4. Reflected spectrum as measured by the upper FBG installed in the WEST tokamak with a coolant loop at $70{ }^{\circ} \mathrm{C}$. (the standard temperature of the machine before plasma operation) is presented in Fig. 4 for one of the two upper FBGs (once regeneration has been realized). Even if the overall reflected signal is low due to the regeneration process, the Bragg peak is about $5 \mathrm{~dB}$ higher than the baseline which is enough for peak detection. The baseline reflected light also shows some fluctuation attributed to back (Fresnel) reflection at the extremity of the fiber.

\section{B. Signal processing and temperature calibration}

The first step which further defines the accuracy of the temperature measurement is to get the position of the Bragg peaks in the experimental spectrum (see Fig. 3). For each FBG, the peak is detected using a Gaussian-shape function (non-linear regression) combined with data filtering and amplification due to the relatively low reflectivity of the gratings and the Fresnel reflection introduced at the extremity of the fiber. The following step is the temperature calibration of the sensing line. The sensing lines are positioned in a high temperature furnace together with a bundle of thermocouples to get the temperature distribution along the furnace. The temperature is first raised to $800{ }^{\circ} \mathrm{C}$, and then heating is switch-off in order to get a slow and regular temperature decrease. The logarithm decrease in the furnace temperature is fitted for all the Bragg wavelengths using a fifth-order polynomial function. Figure 5 shows the 11 calibration curves, one curve for each

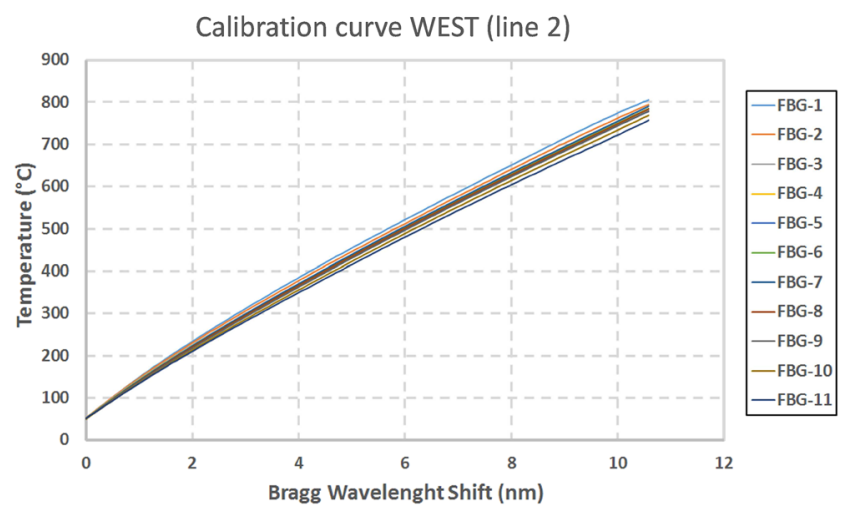

FIG. 5. Calibration curve for one of the 4 sensing lines developed and manufactured for WEST.
FBG, for one of the four sensing lines developed for WEST. Above $800^{\circ} \mathrm{C}$, the calibration curve can be extrapolated based on the polynomial function.

\section{INTEGRATION OF THE FBG DIAGNOSTIC IN WEST}

\section{A. Integration in the W-coated graphite PFU}

The FBG temperature probe is inserted in the LFS graphite PFU through a $4 \mathrm{~mm}$ deep $1.2 \mathrm{~mm}$ thick lateral groove, as shown in Fig. 6(a). The probe has a diameter of $1 \mathrm{~mm}$ (due to the capillary), is $150 \mathrm{~mm}$ long, and has curvature of $R=62 \mathrm{~mm}$ downward toward the pumping duct [Fig. 6(b)]. The $4 \mathrm{~mm}$ deep lateral groove is shown in Fig. 6(c) for the upper FBG (the center located at $3.5 \mathrm{~mm}$ from the surface). The temperature probe is fixed to the component with graphite adhesive made for use up to $1300{ }^{\circ} \mathrm{C}$. After assembling of the instrumented $\mathrm{PFU}$, the connector is clamped to the divertor support plate to prevent any excessive vibration and stresses on the graphite adhesive. A stainless steel box is finally used to protect the overall system from accidental impact during the introduction of the fully equipped divertor sector into the machine. The computer aided design (CAD) view and picture of the FBG system after assembling are presented in Fig. 7. The deployment of the FBG system in WEST is based on one set of two optical fibers, upper and lower FBG which are installed in two adjacent PFU, duplicated in two different divertor sectors (each sector having $30^{\circ}$ toroidal extension).

The four temperature probes are connected to a $3 \mathrm{~m}$ long optical fiber with a protective sheath made of PEEK composite, one of the few plastics compatible with high vacuum and high temperature applications. The overall is protected by a flexible stainless steel creased hose $\varnothing=2.3 \mathrm{~mm}$, up to the sealing flange. In the region between the stainless steel box and the entrance of the pumping duct, the flexible stainless steel creased hose might be exposed to plasma radiation and neutral particles up to $10 \mathrm{~kW} \mathrm{~m}^{-2}$, as shown in Ref. 15 which is acceptable for the temperature behavior of the cable. Each sensing line is connected to a vacuum feedthrough $\left(10^{-8} \mathrm{mbar}\right.$ $1 / \mathrm{s}$ ) located few meters below the machine. At the outside of the vacuum vessel, the system is connected to the FBG interrogator and acquisition system with a $60 \mathrm{~m}$ long remote fiber cable (see Fig. 8). 

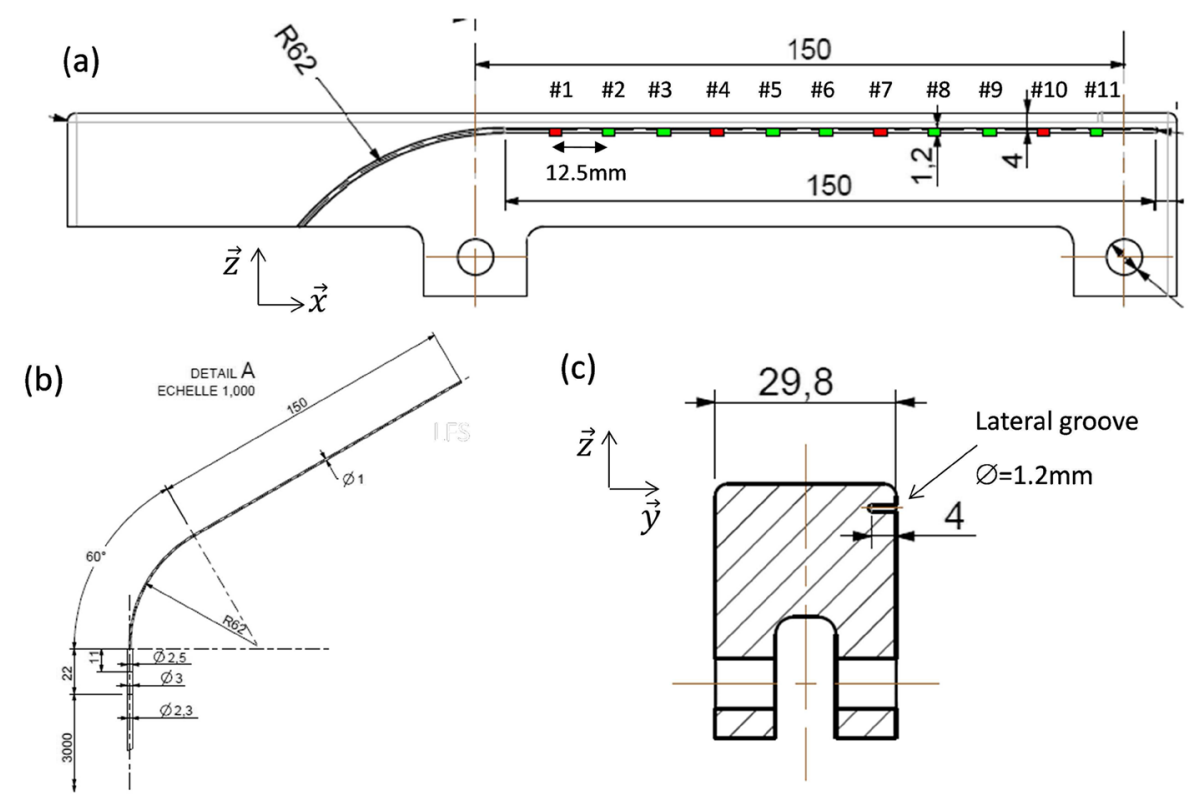

FIG. 6. Fabrication plan for the FBG upper diagnostic embedded in a $1.2 \mathrm{~mm}$ diameter lateral groove at $3.5 \mathrm{~mm}$ below the surface. (a) Drawing showing the sensing line integrated in the W-coated graphite component (side view). (b) Full fiber including the $150 \mathrm{~mm}$ long sensing line and the connection part, followed by a $3 \mathrm{~m}$ flexible capillary to reach the sealing flange. (c) Drawing of the W-coated graphite component showing the lateral groove (back view).
426

427

428

429

430

43

432

433

434

435

436

436
437
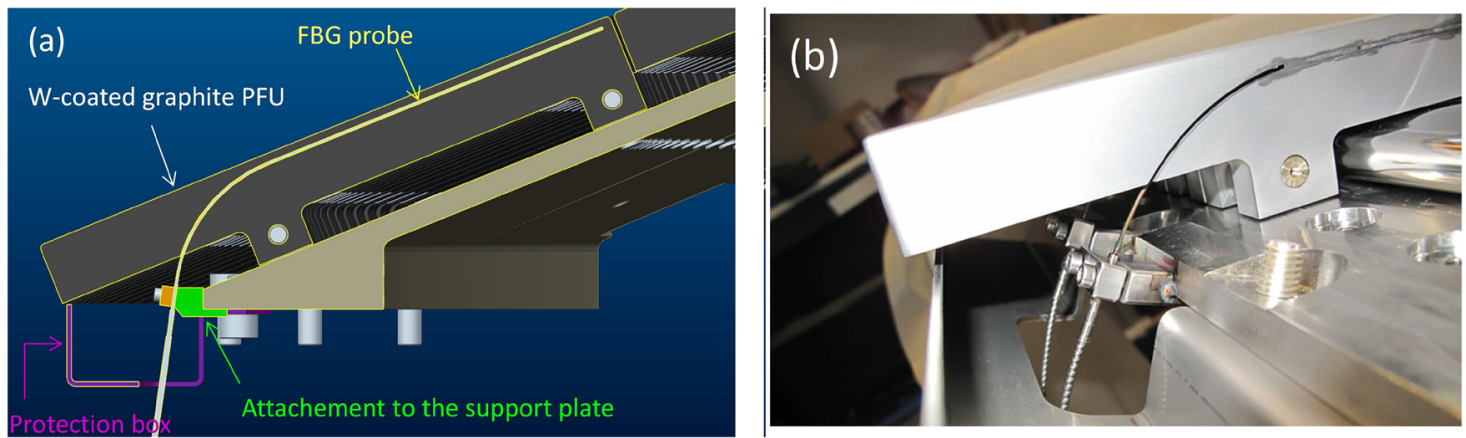

FIG. 7. (a) CAD view showing the FBG upper system (located $3.5 \mathrm{~mm}$ below the surface). (b) Picture showing the FBG lower (located 7 mm below the surface)
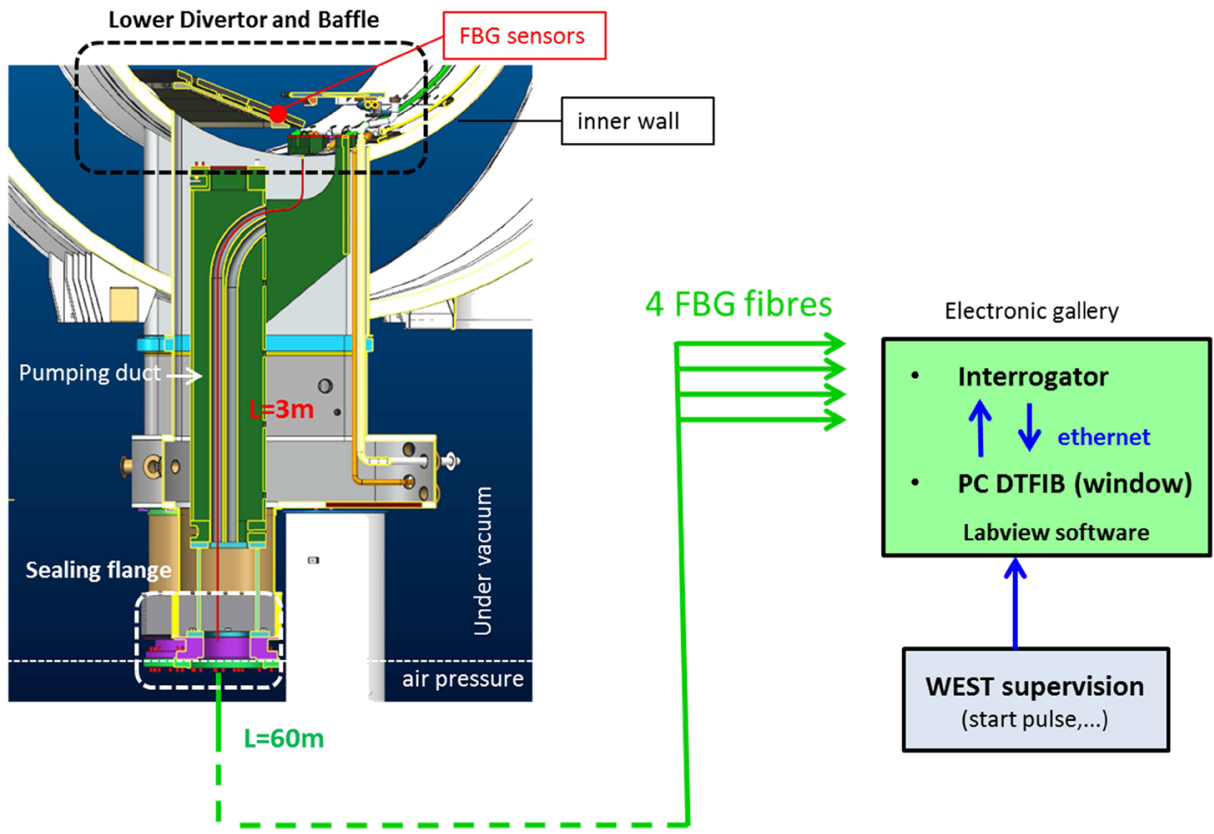

FIG. 8. Overview of the DTFIB\#1 diagnostic as deployed in WEST including drawing of the lower divertor, pumping duct, and sealing flange followed by a schematic view of the data acquisition system. 


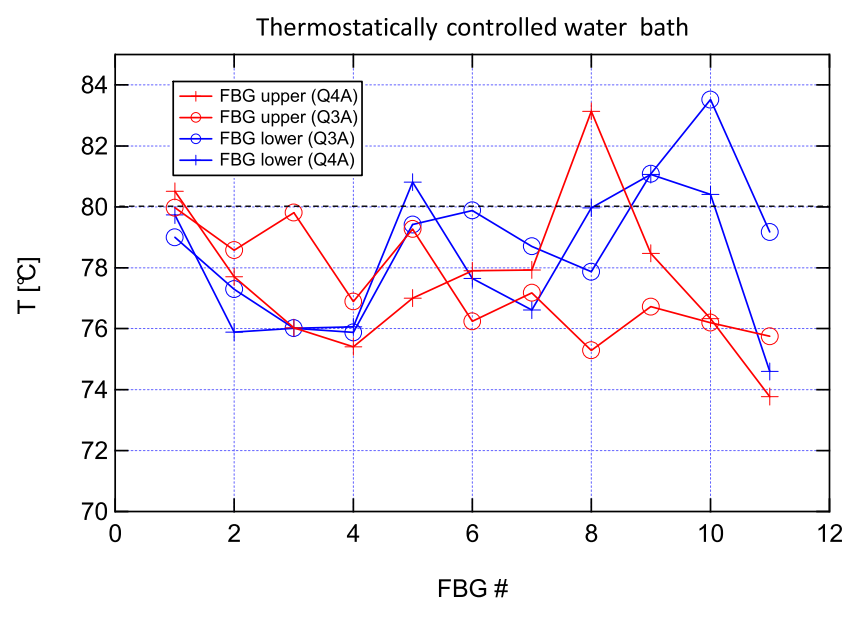

FIG. 9. Averaged temperature measurement performed by the FBG system, including FBG upper (located $3.5 \mathrm{~mm}$ below the surface) and lower $(7 \mathrm{~mm}$ below the surface) optical fibers further duplicated in two different divertor sectors (named Q3A and Q4A, each sector having $30^{\circ}$ toroidal extension), fully immersed in thermostatically controlled water bath at $80^{\circ} \mathrm{C}$.

\section{TEST AND QUALIFICATION OF THE WEST FBG DIAGNOSTIC}

The full multiplexed FBG system has been manufactured by the CEA List Institute and delivered in June 2016. The system has been tested in the laboratory before the implementation in the tokamak. The laboratory tests include three successive experiments to characterize the performance of the system: a thermostatically controlled water bath, high temperature furnace, and fully instrumented PFU with a set of six halogen lamps.

\section{A. Thermostatically controlled water bath}

The four sensing lines are fully immersed (without any component), one after the other, in a thermostatically controlled water bath at $80{ }^{\circ} \mathrm{C}$. The results obtained for each of the 44 FBGs are presented in Fig. 9. The standard deviation obtained at $80^{\circ} \mathrm{C}$ is $\pm 5^{\circ}$, and the temporal variation is below $0.4^{\circ}$ which is consistent with the specification of the system.

\section{B. High temperature furnace}

The FBGs are tested successively (without any component) in a high temperature tubular furnace at the atmospheric pressure. Type-N TCs are used to get the temperature in the furnace with a temperature stability of $\pm 1^{\circ} \mathrm{C}$. The furnace is open at the extremity on the entrance side; therefore, the temperature is close to the setpoint value at the bottom and lower at the entrance sides, respectively. The experimental setup and results obtained for a set of three FBGs are presented in Fig. 10. In the experiment presented here, the instruments are introduced in the furnace for about $150 \mathrm{~s}$ at $250^{\circ} \mathrm{C}$. The overall dynamic of the TC/FBG measurements is coherent during the transitory phase. FBG\#11 heats up first, followed by FBG\#8 and \#6, as we introduce and take away the sensors (slow movement) in the furnace. After their introduction, the FBG fiber and TC are rapidly thermalized with the furnace and the steady state condition is almost reached. The TC measurements are coherent with the positioning; we found $243{ }^{\circ} \mathrm{C}$ at the bottom, $240{ }^{\circ} \mathrm{C}$ in the middle, and $228^{\circ} \mathrm{C}$ close to the entrance. Although the overall dynamic is well reproduced with the FBG measurements, the absolute values given by FBG are slightly different from TC: FBG\#11 shows $10{ }^{\circ} \mathrm{C}$ discrepancy with the TC, while FBG\#8 shows less than $1^{\circ}$ and \#6 less than $3{ }^{\circ} \mathrm{C}$ along the temperature excursion. Such a discrepancy can be attributed to sensor positioning in the furnace, thermal convection in the furnace which is open at the entrance, or FBG calibration and accuracy of the system itself. Among the tested FBGs, the maximum discrepancy is found to be $10{ }^{\circ} \mathrm{C}$ with a temperature furnace of $250{ }^{\circ} \mathrm{C}$ which is, nonetheless, consistent with the specification of the system.

\section{Fully instrumented PFUs heated with halogen lamps}

After the test and characterization of the four FBG systems standalone, the FBG probes are then fixed in the lateral grooves of the W-coated graphite PFUs with graphite adhesive. The fully instrumented PFUs are tested in the laboratory using halogen lamps. Besides the four FBG instrumented PFUs, a fifth PFU is used with 4 embedded thermocouples to derive the thermal time constant of the two systems, the TC and FBG fibre, in the material. The halogen lamp system delivers about $4 \mathrm{~kW} \mathrm{~m}^{-2}$ continuous and quasi-homogeneous power on each target. The five PFUs are pre-heated to about $80{ }^{\circ} \mathrm{C}$ (which is slightly above the nominal temperature of the water cooling system in WEST), this is followed by a 10 min switch-off of the power to thermalize the component, and then we apply successive $30 \mathrm{~s}$-on, $150 \mathrm{~s}$-off power steps to compute the time response of the different diagnostics $\left(\tau_{\text {diag }}\right)$. The experimental setup is presented in Fig. 11(a) and the measurements are presented in Fig. 11(b) for TC and one FBG probe. We report very good dynamic behaviors of the different systems and accurate (a)

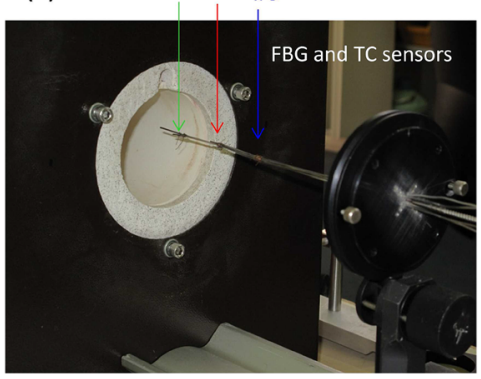

(b)

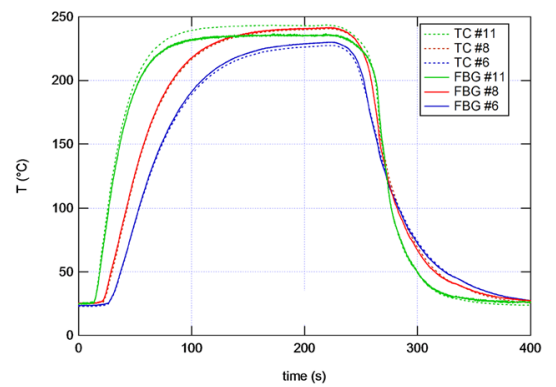

FIG. 10. (a) Picture of the experimental setup before the introduction of the TC and FBG sensors into the tubular furnace. (b) TC and FBG temperature measurements at three different locations (FBG \#6, \#8, and \#11) with a set point temperature of $250{ }^{\circ} \mathrm{C}$. 

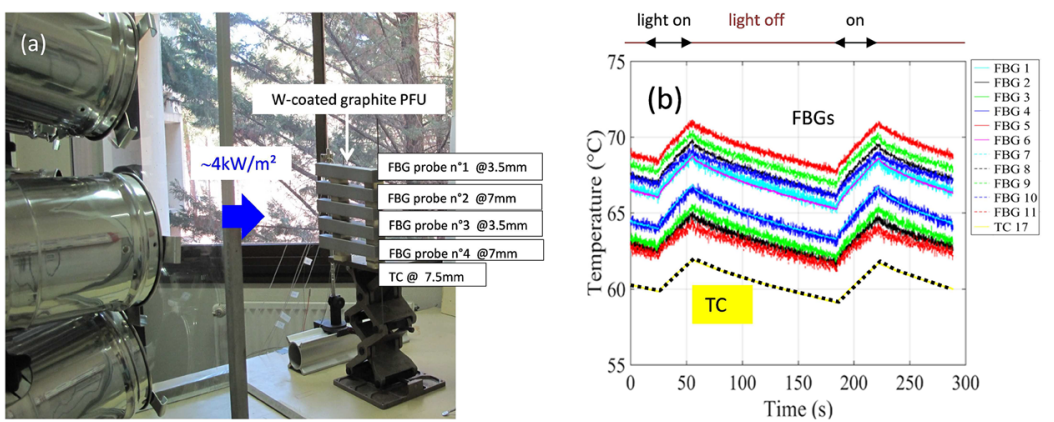

FIG. 11. (a) Picture of the experimental setup with FBG and TC embedded in the W-coated graphite PFUs and halogen heating system. (b) Temperature excursion during $30 \mathrm{~s}$ heating steps of the PFUs as measured with TC (yellow signal) and one FBG probe (11 spots measurements). measurement of the relative heating $\left(\Delta \mathrm{T}=2{ }^{\circ} \mathrm{C}\right.$ during each power step). However, we also report about $8{ }^{\circ} \mathrm{C}$ discrepancy between the two extreme FBGs temperature measurements, similar to the previous experiment. TC data (yellow curve) are slightly lower than FBGs data because the fifth PFU including the TC is slightly out of the center of the beam light [at the bottom as shown in Fig. 11(a)]. The time response of the diagnostic is determined with 2D FEM thermal modeling of the component. The heating is assumed to be uniform along the PFU (the $\mathrm{x}$ direction) so that the geometry can be simplified in the toroidal-vertical plan $(\mathrm{y}, \mathrm{z})$. The numerical temperature reported at the sensor location is convoluted to the temporal step response of the full system (component with the instrument),

$$
u(t)=1-e^{-\frac{t}{\tau_{\text {diag }}}},
$$

where $\tau_{\text {diag }}$ is the time response of the system which is estimated with a Particle Swarm Optimization (PSO) algorithm ${ }^{18}$ in order to minimize the residuals between the model and the measurement. We found $\tau_{\text {diag }}=250 \mathrm{~ms}$ with $\pm 50 \mathrm{~ms}$ standard deviation attributed mainly to the lighting up and electrical stability of the lamps.

\section{BAKING AND EARLY DIVERTED PLASMA EXPOSURE}

The full FBG system has been installed in the WEST tokamak beginning of 2017, before the first plasma breakdown attempts. The system is working properly for more than one year, and we have been able to investigate the variation of temperature during the baking of the machine and during early

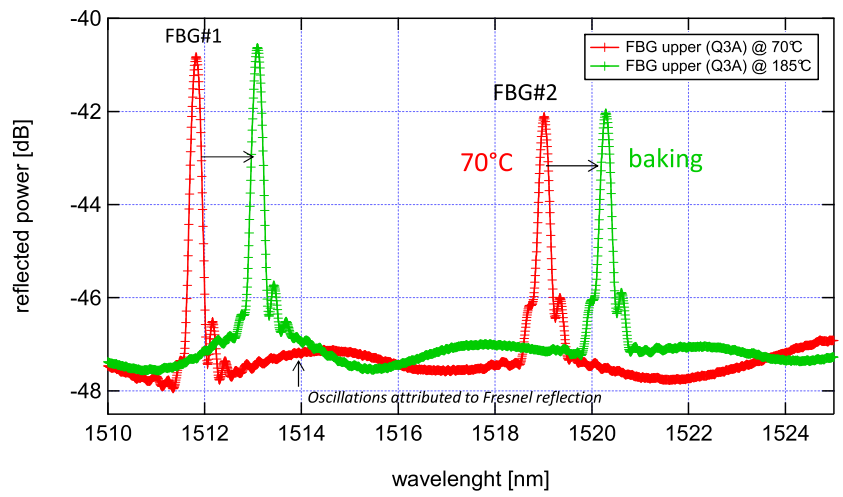

FIG. 12. Reflected power as a function of the wavelength at $70{ }^{\circ} \mathrm{C}$ (red) and during baking at $185^{\circ} \mathrm{C}$ (green), focus on the first and second FBG. diverted plasma exposure. During baking, the water cooling system is raised up to $185^{\circ} \mathrm{C}$ in order to remove the remaining gas from the wall. As a consequence, the temperature is similar in all the PFUs of the divertor. This provides the opportunity to check the FBG temperature measurement in a real tokamak environment by comparing the results with the set of 20 embedded TCs also available in the W-coated graphite PFUs. The reflected power passing through one of the FBG probes and measured by using the spectrometer is presented in Fig. 12 with a specific focus on the two first FBG \#1 and \#2. The resulting signal is about $4 \mathrm{~dB}$ above the baseline signal of the spectrum and therefore adequate to detect the position of the Bragg peak. The shift of the Bragg peak measured during baking is also illustrated.

The temperature measurements of the four FBG probes during baking (performed in April 2017) are presented in Fig. 13 together with the average of the TC measurements. The averaged value for the 44 FBG measurements is $\left\langle\mathrm{T}^{\mathrm{FBG}}\right\rangle$ $=177.6{ }^{\circ} \mathrm{C}$, while the $\mathrm{TC}$ averaged value is $\left\langle\mathrm{T}^{\mathrm{TC}}\right\rangle=186^{\circ} \mathrm{C}$, close to the water temperature. This shows that FBG measurements have an offset of $10{ }^{\circ} \mathrm{C}$ lower than expected. Data scattering of the FBG measurements is about $\pm 10{ }^{\circ} \mathrm{C}$ around the averaged value. These discrepancies are attributed to the FBG calibration and peak detection algorithm which are currently under review to improve the data processing (some fluctuation of the baseline signal of the spectrum is observed and attributed

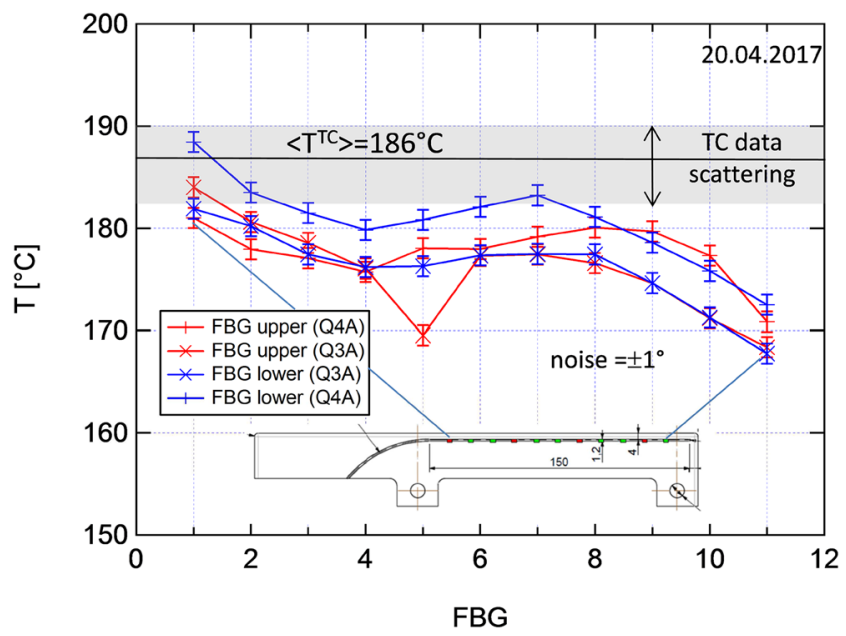

FIG. 13. Temperature measurement with FBG located in two different divertor sectors (named Q3A and Q4A, plotted with cross and plus signs, respectively) and TC systems during baking. FBG upper ( $3.5 \mathrm{~mm}$ below the surface) and lower ( $7 \mathrm{~mm}$ below the surface) are plotted in red and blue, respectively. 

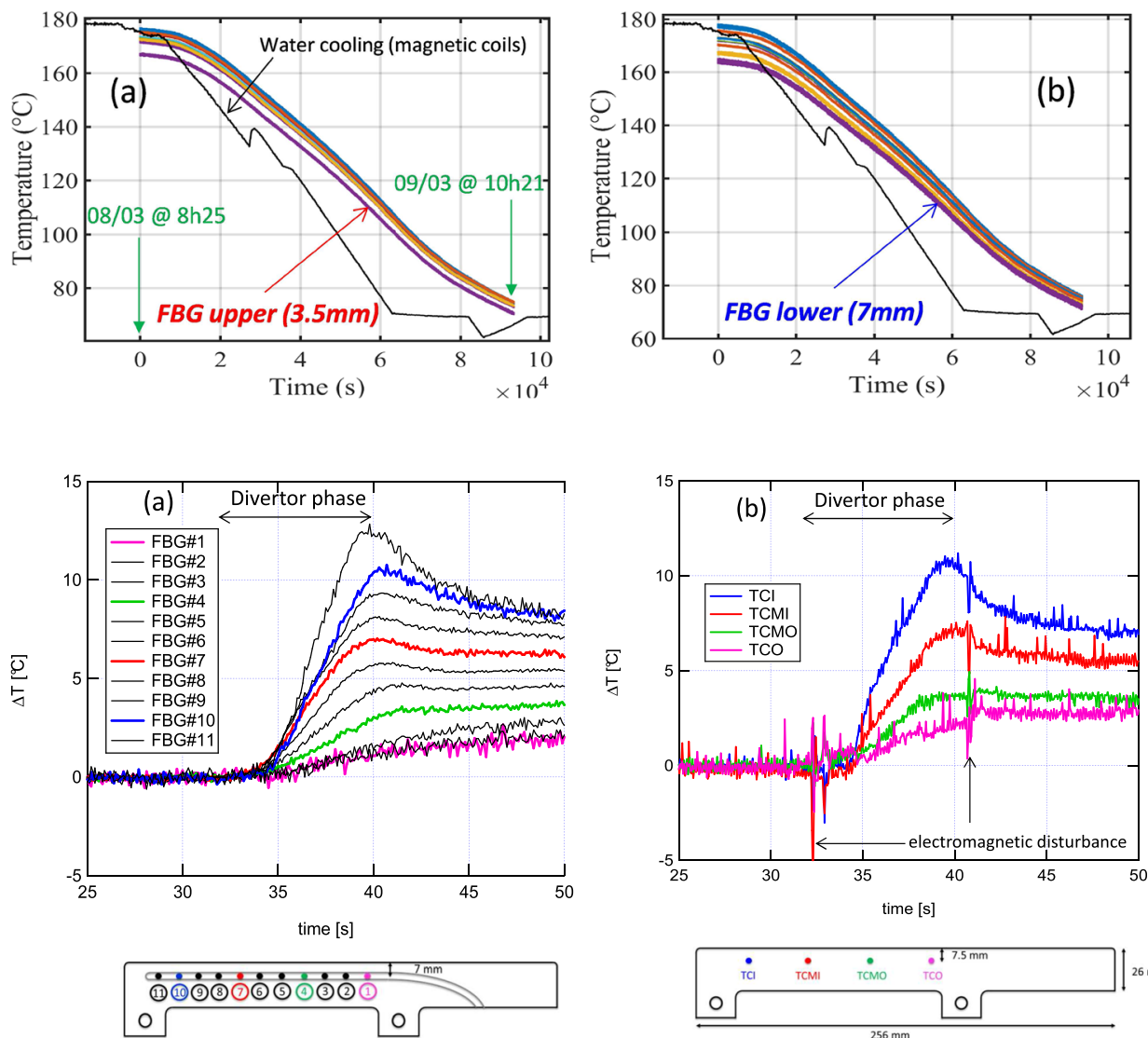

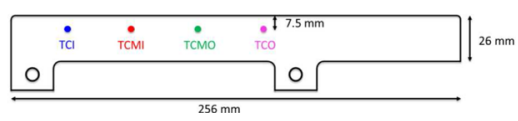

FIG. 14. Temporal evolution of the temperature during the cooling down, from baking of the machine down to $70{ }^{\circ} \mathrm{C}$, as measured by FBG upper (a) and lower (b).
FIG. 15. Heating measured with the FBG lower (a) and embedded thermocouples diagnostics (b) during early WEST diverted plasma exposure (\#52693). The diverted plasma exposure lasts for about $7.2 \mathrm{~s}$, from $32.8 \mathrm{~s}$ up to $40 \mathrm{~s}$. to the Fresnel reflection introduced at the extremity of the fiber).

Figure 14 shows the temporal evolution of the temperature as measured with the FBG upper (a) and lower (b) probes as well as the temperature of the water in the cooling loop of the divertor coils (the signal called here as TTBB) at the end of another baking phase (performed in March 2017) when the temperature of the machine decreases down to $70{ }^{\circ} \mathrm{C}$ for plasma operation. The typical duration to heat or cool the machine for baking is $24 \mathrm{~h}$. As for the laboratory experiment with the halogen lamps, the absolute value shows a $10{ }^{\circ} \mathrm{C}$ offset with the expected temperature, but it is important to stress that the overall heating or cooling is well reproduced (we found $\Delta \mathrm{T}=110{ }^{\circ} \mathrm{C}$ between the normal condition and baking)

Plasma breakdown, plasma current ramp-up, and diverted plasma have been developed after the machine commissioning. First diverted plasmas with additional heating power have been achieved in WEST in early 2018. Figures 15(a) and 15(b) show the temporal evolution of the temperature rise as measured with the FBG (DTFIB\#1) and thermocouple diagnostics, respectively, during a $700 \mathrm{kA}$ plasma current diverted plasma experiment (\#52693). The thermocouples are embedded at $7.5 \mathrm{~mm}$ distance from the surface of the PFU, close to the lower FBG probes that are embedded at $7 \mathrm{~mm}$. The space between two thermocouples is $37.5 \mathrm{~mm}$, while it is $12.5 \mathrm{~mm}$ between two FBG spot measurements (we have therefore one thermocouple every three FBG spot measurements). The two different systems show similar heating distribution along the PFU and similar intensities. Looking at the signal variation as a function of time first, we clearly see the benefit of the optical solution (with noise measurement $\leq 1^{\circ}$ ) compared to electrical measurement such as TC data which are more sensitive to electromagnetic disturbance (up to few degrees, variation is observed during the plasma current ramp up and ramp down phases). Second, looking at the signal intensity, about $11^{\circ}$ heating is reported on FBG\#10 and thermocouple TCI at the end of the pulse (blue curves), both sensors being located at the same position along the PFU. Such a temperature rise, regarding the duration of the pulse, corresponds to plasma heat flux of about $100 \mathrm{~kW} \mathrm{~m}^{-2}$, a value which is small but also coherent, on top of the TC measurements, with Langmuir probe measurements. The FBG and TC data presented here were obtained in the very first WEST plasmas having an important level of radiated power losses. Further experiments will aim at decreasing radiated power fraction while increasing injected power.

\section{CONCLUSION}

This paper shows the design and integration of the new embedded FBG diagnostic called DTFIB\#1 to monitor the PFU temperature during tokamak plasma operation. Four high temperature probes including each having eleven FBGs have been specifically designed and manufactured by the CEA List Institute according to the WEST plasma and material conditions. Each sensing part of probe is inserted in the PFU through a tiny lateral groove (at two different depths $3.5 \mathrm{~mm}$ and $7 \mathrm{~mm}$ ) and attached with graphite adhesive. The multiplexed and regenerated FBG probes have been 
tested and characterized in three laboratory experiments before installation in the machine. The accuracy of the measurement is found to be about $10{ }^{\circ} \mathrm{C}$ at low temperatures (up to about $250{ }^{\circ} \mathrm{C}$ in the tubular furnace), which meets the specification even if there is still some margin for improvement (the calibration and peak detection algorithm are currently under review). However, the relative heating of the component which will be further used to compute the absorbed heat load is well reproduced. The time response of the FBG diagnostic in the component is found to be $250 \mathrm{~ms}$ with $\pm 50 \mathrm{~ms}$ standard deviation, which is relatively small compared to the standard duration of the plasma experiment in WEST (from several seconds up to couple of minutes). The diagnostic DTFIB\#1 has been installed in the real tokamak environment and successfully tested during baking (up to $185^{\circ} \mathrm{C}$ in WEST) and early diverted plasma exposure (with high radiated power losses and a small amount of power reaching the divertor). It is now foreseen to use the 44 available spot measurements of the new FBG diagnostic to cross-check the IR thermography measurement and characterize the heat load absorbed by the components over the coming plasma experiments. The next step will be to ensure that the diagnostic is working properly during plasma operation with high heat flux and high temperature in the lower divertor.

\section{ACKNOWLEDGMENTS}

We wish to thank our colleagues Jean-Claude Vallet, at the CEA IRFM Institute, to have had the bold idea of using FBG sensors in WEST and Pierre Ferdinand, at the CEA List Institute, for his enthusiasm to commit to working in close cooperation with the two institutes. This work has been carried out with the support of the A*MIDEX Project (No. ANR11-IDEX-0001-02) funded by the "Investissements d'Avenir"
French Government program, managed by the French National Research Agency (ANR).

${ }^{1}$ G. Laffont, R. Cotillard, and P. Ferdinand, Meas. Sci. Technol. 24, 094010 (2013), (5p.).

${ }^{2}$ A. Poncet, S. Brun, A. Foussat, R. Gallix, J. Knaster, F. Rodriguez-Mateos, and F. Simon, IEEE Trans. Appl. Supercond. 22(3), 9500604 (2012).

${ }^{3}$ A. Li Puma, G. Aiello, F. Gabriel, G. Laffont, G. Rampal, and J.-F. Salavy, Fusion Eng. Des. 85, 1642-1652 (2010).

${ }^{4}$ K. Ioki, A. Bayon, C. H. Choi, E. Daly, S. Dani, J. Davis, B. Giraud, Y. Gribov, C. Hamlyn-Harris, C. Jun, B. Levesy, B. C. Kim, E. Kuzmin, R. Le Barbier, J.-M. Martinez, H. Pathak, J. Preble, J. W. Sa, A. Terasawa, Yu. Utin, and X. Wang, Fusion Eng. Des. 88, 590-596 (2013).

${ }^{5}$ C. Lescure, S. Hotchin, E. Ivings, M. F. Johnson, V. Riccard, M. Walsh, and A. West, in 23rd IEEE/NPSS Symposium on Fusion Engineering (SOFE 2009) (IEEE, 2009).

${ }^{6}$ C. Vorpahl, W. Suttrop, M. Ebner, B. Streibl, H. Zohm, and ASDEX Upgrade Team, Fusion Eng. Des. 88, 537-540 (2013).

${ }^{7}$ S. Pal, J. Mandal, T. Sun, K. T. V. Grattan, M. Fokine, F. Carlsson, P. Y. Fonjallaz, S. A. Wade, and S. F. Collins, Meas. Sci. Technol. 14, 1131-1136 (2003).

${ }^{8}$ J. Bucalossi et al., Fusion Eng. Des. 89, 907-912 (2014).

${ }^{9}$ S. Carpentier-Chouchana et al., Phys. Scr. T159, 014002 (2014), (7p.).

${ }^{10}$ T. Hirai et al., Nucl. Mater. Energy 000, 1-7 (2016).

${ }^{11}$ M. Missirlian et al., Fusion Eng. Des. 89, 1048-1053 (2014).

${ }^{12}$ M. Firdaouss, Y. Corre, P. Languille, H. Greuner, E. Autissier, C. Desgranges, D. Guilhem, J. P. Gunn, M. Lipa, M. Missirlian, J.-Y. Pascal, C. Pocheau, M. Richou, and E. Tsitrone, Phys. Scr. T167, 014012 (2016).

${ }^{13}$ M.-H. Aumeunier, M. Kocan, R. Reichle, and E. Gauthier, Nucl. Mater. Energy 000, 1-5 (2017).

${ }^{14}$ J. Gaspar, Y. Corre, J.-L. Gardarein, M. Firdaouss, D. Guilhem, M. Houry, G. Laffont, C. Le Niliot, M. Missirlian, C. Pocheau, and F. Rigollet, Nucl. Mater. Energy 000, 1-5 (2016).

${ }^{15}$ H. Bufferand, G. Ciraolo, Y. Marandet, J. Bucalossi, Ph. Ghendrih, J. Gunn, N. Mellet, P. Tamain, R. Leybros, N. Fedorczak, F. Schwander, and E. Serre, Nucl. Fusion 55, 053025 (2015), (9p.).

${ }^{16}$ T. Eich et al., J. Nucl. Mater. 438, S72-S77 (2013).

${ }^{17}$ K. O. Hill and G. Meltz, J. Lightwave Technol. 15(8), 1263 (1997).

${ }^{18}$ J. Kennedy and R. Eberhart, "Particle swarm optimization," in Proceedings of the IEEE International Conference on Neural Networks (IEEE, 1995).

${ }^{19}$ The edge plasma refers to the external part of the plasma where magnetic field lines connect to the material surfaces. 